Chapman University

Chapman University Digital Commons

Pharmacy Faculty Articles and Research

School of Pharmacy

$10-6-2011$

\title{
Neuroprotective Effects of Bilobalide are Accompanied by a Reduction of Ischemia-Induced Glutamate Release in vivo
}

\author{
Dorothee Lang \\ Goethe University Frankfurt \\ Cornelia Kiewert \\ Texas Tech University Health Science Center \\ Alexander Mdzinarishvili \\ Texas Tech University Health Science Center \\ Tina Maria Schwarzkopf \\ Goethe University Frankfurt \\ Rachita K. Sumbria \\ Chapman University, sumbria@chapman.edu
} Follow this and additional works at: https://digitalcommons.chapman.edu/pharmacy_articles

Part of the Animal Experimentation and Research Commons, Medical Neurobiology Commons, Nervous System Diseases Commons, Other Chemicals and Drugs Commons, Other Pharmacy and Pharmaceutical Sciences Commons, Pharmaceutical Preparations Commons, and the Therapeutics Commons

\section{Recommended Citation}

Lang D, Kiewert C, Mdzinarishvili A, et al. Neuroprotective effects of bilobalide are accompanied by a reduction of ischemia-induced glutamate release in vivo. Brain Res. 2011;1425:155-63. https://doi.org/ 10.1016/j.brainres.2011.10.005

This Article is brought to you for free and open access by the School of Pharmacy at Chapman University Digital Commons. It has been accepted for inclusion in Pharmacy Faculty Articles and Research by an authorized administrator of Chapman University Digital Commons. For more information, please contact laughtin@chapman.edu. 


\section{Neuroprotective Effects of Bilobalide are Accompanied by a Reduction of Ischemia-Induced Glutamate Release in vivo}

\section{Comments}

NOTICE: this is the author's version of a work that was accepted for publication in Brain Research. Changes resulting from the publishing process, such as peer review, editing, corrections, structural formatting, and other quality control mechanisms may not be reflected in this document. Changes may have been made to this work since it was submitted for publication. A definitive version was subsequently published in Brain Research, volume 1425, in 2011. https://doi.org/10.1016/j.brainres.2011.10.005

The Creative Commons license below applies only to this version of the article.

\section{Creative Commons License}

\section{(c) $($ ) $(8)$}

This work is licensed under a Creative Commons Attribution-Noncommercial-No Derivative Works 4.0 License.

\section{Copyright}

Elsevier

\section{Authors}

Dorothee Lang, Cornelia Kiewert, Alexander Mdzinarishvili, Tina Maria Schwarzkopf, Rachita K. Sumbria, Joachim Hartmann, and Jochen Klein 


\title{
Neuroprotective effects of bilobalide are accompanied by a reduction of ischemia-induced glutamate release in vivo
}

\author{
Dorothee Lang ${ }^{\mathrm{a}, 1}$, Cornelia Kiewert ${ }^{\mathrm{b}, 1}$, Alexander Mdzinarishvili ${ }^{\mathrm{b}, \mathrm{c}}$, Tina Maria \\ Schwarzkopf $^{\mathrm{a}}$, Rachita Sumbria ${ }^{\mathrm{b}}$, Joachim Hartmann ${ }^{\mathrm{b}}$, and Jochen Klein ${ }^{\mathrm{a}, \mathrm{b}}{ }^{,}$ \\ a Department of Pharmacology, College of Pharmacy, Goethe University Frankfurt, Max-von- \\ Laue-Str. 9, 60438 Frankfurt, Germany \\ b Department of Pharmaceutical Sciences, School of Pharmacy, Texas Tech University Health \\ Science Center, 1300 Coulter Dr, Amarillo, TX 79106, USA \\ c Department of Pharmaceutical Sciences, Northeastern Ohio University School of Pharmacy, \\ 4209 State Road 44, Rootstown, OH 44272, USA
}

\begin{abstract}
Neuroprotective properties of bilobalide, a specific constituent of Ginkgo extracts, were tested in a mouse model of stroke. After 24 hours of middle cerebral artery occlusion (MCAO), bilobalide reduced infarct areas in the core region (striatum) by 40-50\% when given at $10 \mathrm{mg} / \mathrm{kg}$ one hour prior to MCAO. Neuroprotection was also observed at lower doses, or when the drug was given 1 $\mathrm{h}$ past stroke induction. Sensorimotor function in mice was improved by bilobalide as shown by corner and chimney tests. When brain metabolism in situ was monitored by microdialysis, MCAO caused a rapid disappearance of extracellular glucose in the striatum which returned to baseline levels after reperfusion. Extracellular levels of glutamate were increased by more than ten-fold in striatal tissue, and by four- to fivefold in hippocampal tissue (penumbra). Bilobalide did not affect glucose levels but strongly attenuated glutamate release in both core and penumbra regions. Bilobalide was equally active when given locally via the microdialysis probe and also reduced ischemia-induced glutamate release in vitro in brain slices. We conclude that bilobalide is a strong neuroprotectant in vivo at doses that can be used therapeutically in humans. The mechanism of action evidently involves reduction of glutamate release, thereby reducing excitotoxicity.
\end{abstract}

\section{Keywords}

Ginkgo biloba; glucose; microdialysis; middle cerebral artery occulsion; stroke

\section{Introduction}

Neuroprotection, i.e. the prevention of nerve cell death, remains a prominent goal for the prevention and therapy of stroke-related damage (Woodruff et al., 2011). To the frustration of researchers and clinicians, however, many approaches that were effective in experimental

\footnotetext{
(C) 2011 Elsevier B.V. All rights reserved.

*Corresponding author. Phone +49-69 798 29366. FAX +49-69 798 29277. klein@em.uni-frankfurt.de.

${ }^{1}$ Equal contribution to the paper.

Publisher's Disclaimer: This is a PDF file of an unedited manuscript that has been accepted for publication. As a service to our customers we are providing this early version of the manuscript. The manuscript will undergo copyediting, typesetting, and review of the resulting proof before it is published in its final citable form. Please note that during the production process errors may be discovered which could affect the content, and all legal disclaimers that apply to the journal pertain.
} 
stroke models failed to elicit beneficial effects in clinical studies (Ginsberg, 2008). While poor drug properties, e.g. insufficient brain permeability, were responsible for some failures, many neuroprotective compounds failed because of the time window of drug effects; as a rule, most compounds only acted when given prior to stroke induction which rendered them useless for clinical use. Preventive application of neuroprotective drugs would be preferable but is often limited by intolerable side effects. Therefore, tolerability is of major importance for current research into neuroprotective drugs (Danton and Dietrich, 2004).

Extracts of Ginkgo biloba are widely used for the treatment of chronic neurodegenerative disorders such as Alzheimer's disease (Birks and Grimley, 2009) and are well tolerated. In clinical trials, the well-known Ginkgo extract EGb761 has been almost devoid of side effects although a potential to inhibit blood coagulation is still under discussion. Importantly, more than 20 years of experimental work has amply demonstrated that Ginkgo extracts exert beneficial effects in animal models of acute neurodegeneration, e.g. in cerebral hypoxia and ischemia (Lee et al., 2002; reviewed by Ahlemeyer and Krieglstein, 2003). However, high doses of extracts $(50-200 \mathrm{mg} / \mathrm{kg}$ ) were usually required for optimum efficacy, and use of specific compounds at lower doses may be advantageous.

In earlier work, we had investigated specific constituents of Ginkgo extracts in an in vitromodel of brain slices exposed to hypoxia and excitotoxicity, and we had reported that the effectiveness of Ginkgo extract EGb761 in this model was exclusively due to the presence of bilobalide, a sesquiterpene lactone that constitutes 2.9-3.2\% of the extract (Klein et al., 1997; Weichel et al., 1999). Bilobalide was also identified as active ingredient by other groups (Chandradsekaran et al., 2001; reviewed by DeFeudis, 2002). In subsequent work, we further characterized bilobalide's effects in hippocampal slices (Kiewert et al., 2008), and in a preliminary study in vivo, we found that bilobalide strongly reduced brain edema in mice subjected to middle cerebral artery occlusion (Mdzinarishvili et al., 2007). Here, we report dose- and time-dependency of drug action and demonstrate functional improvements of the treated animals. Most importantly, we analyzed bilobalide's site and mechanism of action using microdialysis procedures.

\section{Results}

\subsection{Dose- and time-dependent effects of bilobalide}

We used middle cerebral artery occlusion (MCAO) in mice to induce focal cerebral ischemia in vivo. Figs. 1 and 2 (upper panels) show representative experiments in which infarct areas were stained with TTC 24 hours after permanent occlusion. A total of nine mice was used in each group, from which two mice were excluded from analysis because of extensive bleeding after surgery or death within 24 hours. Among seven successful experiments in each group, the areas of non-viable, infarcted tissue were much smaller when animals were treated with bilobalide; this effect was particularly prominent in the striatal area, the tissue at the core of the infarct. At $10 \mathrm{mg} / \mathrm{kg}$, the drug reduced the infarct area in striatal slices from $52.1 \pm 2.8 \%$ of total area (controls) to $13.1 \pm 8.5 \%(10 \mathrm{mg} / \mathrm{kg})$, respectively (exemplary data for slice \#3, mean \pm SEM, $\mathrm{N}=7$ each). Bilobalide was also significantly active at $3 \mathrm{mg} / \mathrm{kg}$ (infarct area: $30.9 \pm 8.5 \%$; not illustrated) and moderately active at $1 \mathrm{mg} / \mathrm{kg}$ although the effect did not reach statistical significance (Fig. 1). At 0.3 $\mathrm{mg} / \mathrm{kg}$, the drug was ineffective (data not shown). Fig. 2 demonstrates that bilobalide was still strongly effective when the drug was administered one hour after MCAO; here, it reduced stroke area (in slice \#3) from $52.1 \pm 2.8 \%$ (controls) to $16.3 \pm 8.6 \%(10 \mathrm{mg} / \mathrm{kg}$ ). At 3 hours past stroke, a limited protection was seen $(31.1 \pm 5.1 \% ; \mathrm{p}<0.05 ; \mathrm{N}=7$ each) (Fig. 2). 


\subsection{Sensorimotor function}

As bilobalide was most effective when given at $10 \mathrm{mg} / \mathrm{kg}$ one hour before MCAO, we used this dose and time point to test for functional recovery in transiently stroked mice. In the corner test (Fig. 3A), mice did significantly better when bilobalide was given, indicating that right leg function was better preserved after MCAO, concomitant with improved cell viability in the striatum (Fig. 1). In the chimney test (Fig. 3B), stroked mice had difficulties leaving the tube whereas all bilobalide-treated mice quickly climbed out of the tube, at a rate (7-18 s) similar to sham-operated animals (8-15 s).

\subsection{Extracellular levels of glucose and lactate}

Brain neurochemistry in situ was monitored by microdialysis in mouse striatum, the core area of the infarct (Fig. 4A and C), and in the hippocampus, an area belonging to the penumbra, i.e. the area that is only partially damaged by ischemia and can be rescued by neuroprotective drugs (Fig. 4B and D). The microdialysis probe has access to the extracellular space, hence, measured values reflect extracellular concentrations. True extracellular concentrations can be estimated by a comparison of dialyzed concentrations with in vitro-recoveries which were $23.5 \%$ for glucose and $34.9 \%$ for glutamate.

Basal levels of striatal glucose before ischemia were $0.39 \pm 0.11 \mathrm{mM}(\mathrm{N}=52)$ and remained largely unchanged during microdialysis in sham-operated mice (Fig. 4A and B). After MCAO, striatal glucose levels immediately declined by more than $90 \%$ within 20-30 minutes (Fig. 4A). In hippocampus, glucose levels dropped by $75 \%$ upon MCAO but recovered slowly to 50-60\% of baseline values in spite of ongoing MCAO indicating partially preserved blood flow in the penumbra (Fig. 4B). Importantly, pretreatment with bilobalide had no effect on glucose levels in either striatum or hippocampus indicating that neither blood supply nor consumption of glucose was affected by the drug (Fig. 4A and B).

It should be mentioned that we also measured extracellular concentrations of lactate which were $0.34 \pm 0.08 \mathrm{mM}(\mathrm{N}=52)$; however, lactate levels were strongly (several-fold) increased at the onset of anesthesia with isoflurane and therefore, were of little significance to monitor ischemia in our experiments. We have recently described this phenomenon for several volatile anesthetic drugs (Horn and Klein, 2010) and do not further discuss lactate levels in this manuscript.

\subsection{Extracellular levels of glutamate}

Extracellular glutamate levels are much lower than glucose levels; in our experiments, the extracellular concentration of glutamate in the striatum was $3.59 \pm 1.62 \mu \mathrm{M}(\mathrm{N}=30)$. Ischemia is known to lead to the release of large amounts of glutamate from brain cells, a phenomenon that causes massive neurodegeneration by excitotoxicity (Lipton, 1999; Mehta et al., 2007). Accordingly, while glutamate remained at low levels in sham-operated mice, we observed an immediate, very prominent increase of striatal glutamate by (on average) 60-fold (Fig. 4C). Glutamate levels decreased slowly thereafter but remained strongly elevated for at least two hours. In the hippocampus, levels of glutamate were also strongly increased, reaching 1,200-1,500\% of baseline and returning to low levels within 120 minutes (Fig. 4D).

Most importantly, in mice pretreated with bilobalide, glutamate release was strongly attenuated. In the striatum of treated mice, glutamate was released in a delayed fashion, increased slowly and never reached values that exceeded 2,000\% of controls (Fig. 4C). In the hippocampus of treated mice, glutamate levels never exceeded $500 \%$ of hippocampal baseline levels and reached control levels after 60 minutes (Fig. 4D). Reduction of glutamate 
release greatly diminishes excitotoxicity and can explain neuroprotective effects (Lipton, 1999; Mehta et al., 2007).

\subsection{Local administration of bilobalide}

To determine the site of action of bilobalide, MCAO was induced while bilobalide was given locally. For this purpose, bilobalide $(10 \mu \mathrm{M})$ was added to the perfusion fluid and allowed to diffuse into the striatal tissue surrounding the probe ("retrodialysis"). Fig. 5 demonstrates that again, the presence of bilobalide did not affect glucose concentrations (Fig. 5A) but strongly attenuated the local increase of glutamate in the striatum (Fig. 5B). In fact, locally infused bilobalide acted qualitatively similar as systemically applied drug because it both strongly delayed and decreased the ischemia-induced increase of glutamate levels (Fig. 5B). This observation indicates that bilobalide is neuroprotective by local action in the brain.

\section{$2.6\left[{ }^{3} \mathrm{H}\right]$-glutamate release assay}

This assay was established to investigate the effect of bilobalide on glutamate release under in vitro-conditions, i.e. in the absence of blood circulation. We used oxygen-glucose deprivation (OGD) in murine striatal slices as an in vitro-ischemia model and, after preincubating the slices with $\left[{ }^{3} \mathrm{H}\right]$-glutamate, observed an immediate increase of tritium label when OGD conditions were applied (Fig. 6A). More than $85 \%$ of this radioactivity was $\left[{ }^{3} \mathrm{H}\right]$-glutamate as confirmed by TLC (not illustrated). While bilobalide $(10 \mu \mathrm{M})$ did not affect basal release of $\left[{ }^{3} \mathrm{H}\right]$-glutamate, it significantly reduced the ischemia-induced release (Fig. 6A). As estimated from AUC calculations, bilobalide reduced ischemia-induced glutamate release by $65 \%$ ( $<<0.05$; Fig. $6 \mathrm{~B})$.

\subsection{Enzymatic formation of glutamate}

Using mouse brain homogenate, we have investigated two enzymatic activities that were suggested to contribute to glutamate formation in vivo, namely glutaminase (which hydrolyzes glutamine to glutamate) and NAALADase which cleaves glutamate from Nacetylaspartate-glutamate (NAAG). As shown in Table 1, both enzymes were strongly (>90\%) inhibited by their well-known synthetic inhibitors, DON for glutaminase and PMPA for NAALADase. Bilobalide, however, did not significantly affect enzymatic activities suggesting that there must be other targets for this drug (Table 1).

\section{Discussion}

\subsection{Bilobalide as a potential drug}

Poor brain permeability and insufficient time windows of action are two major reasons why promising neuroprotective drugs have failed under clinical conditions (Ginsberg, 2008). Attention should be shifted, therefore, to drugs that either work several hours or days after the stroke has occurred (e.g. protecting cell death by late-onset inflammatory mechanisms) or to drugs that can be used in a prophylactic manner in stroke-prone patients, e.g. patients with long-standing, therapy-resistant hypertension or patients previously suffering from transient ischemic attacks. Ginkgo extracts and their constituents may be promising candidates in this regard because they have been used by many patients over many years in the absence of serious adverse effects (Birks and Grimley, 2009). While Ginkgo biloba extracts lack efficacy when given in the post-stroke recovery period (Zeng et al., 2005), we here report that bilobalide, a specific constituent representing approx. 3\% of Ginkgo extract EGb761, has acute neuroprotective properties in the mouse MCAO model when given before or shortly after stroke. Bilobalide worked best when given at a dose of $10 \mathrm{mg} / \mathrm{kg}$ one hour before stroke; this is in agreement with a previous study in which a plasma half-life of 
approx. 90 minutes was measured in mice (Lang et al., 2010). However, smaller doses and later time points, e.g. one hour after stroke, were also effective (Figs. 1 and 2). At optimum dose, bilobalide reduced striatal stroke areas by more than $50 \%$ and clearly improved the functional outcome as measured by tests of sensorimotor function (Fig. 3). Moreover, in agreement with present results, we have recently reported that bilobalide is brain-permeable and crosses the blood-brain barrier quickly; in fact, it remained in brain tissue in a prolonged manner after ischemia had been induced (Lang et al., 2010). Pure bilobalide, or a Ginkgo extract enriched in bilobalide, could therefore be used for neuroprotection in stroke-prone patients, especially because it can be given in a preventive manner with little potential for adverse side effects.

It should be noted that we measured stroke-induced damage only after 24 hours in this study when neuroprotection was seen in the striatum, a core region of MCAO-induced stroke. Further work is required to ascertain long-term improvement of sensorimotor function in treated mice. However, even if bilobalide does not ultimately prevent neuronal death in core areas of stroke damage, our results indicate that neuronal cell death may be strongly delayed by up to 24 hours. This effect may be beneficial when neuroprotection is combined with thrombolytic therapy because the time window for successful thrombolysis would be extended considerably.

The neuroprotective properties of bilobalide have been described under a variety of conditions (DeFeudis, 2002; Ahlemeyer and Krieglstein, 2003). In vitro, the drug is active in neurons (Ahlemeyer et al., 1999) and in brain slices exposed to hypoxia (Klein et al., 1997; Johns et al., 2002) or excitotoxicity (Weichel et al., 1999). The required concentrations for bilobalide in vitro were in the range of $1-10 \mu \mathrm{M}$; the lowest value $\left(\mathrm{IC}_{50}\right.$ of $\left.0.38 \mu \mathrm{M}\right)$ was observed in our lab for a membrane-protective action in hippocampal slices (Klein et al. 1997) and is close to plasma levels measured in human volunteers ingesting Ginkgo extract EGb761 (Biber, 2003). In mice, administration of the strongly neuroprotective dose of 10 $\mathrm{mg} / \mathrm{kg}$ leads to bilobalide plasma levels of $5.9 \mu \mathrm{M}$ and to brain levels of $0.92 \mu \mathrm{M}$ (Lang et al., 2010). These data show that a moderate enrichment of bilobalide in Ginkgo extracts would be sufficient to obtain plasma levels in humans that are neuroprotective in the mouse.

\subsection{Site and mechanism of action of bilobalide}

The most striking finding of the present study is the specific inhibition of ischemia-induced glutamate release by bilobalide (Figs. 4-6). Previous research has amply demonstrated that the increase of glutamate is one of the major culprits for ischemia-induced neurodegeneration because it causes "excitotoxicity", i.e. massive neuronal depolarisation and calcium overload (reviewed by Lipton, 1999; Szydlowska and Tymianski, 2010). Very recently, we have reported huge increases of glutamate in mouse brain following MCAO (Kiewert et al., 2010), In our present study, the reduction in glutamate levels in bilobalidetreated mice corresponds to a reduction of infarcted area and to an improvement of neurological outcome. We therefore believe that bilobalide's neuroprotective actions on a cellular level are due to attenuation of ischemia-induced glutamate release. Interestingly, reductions of glutamate release have previously been described for neuroprotective actions of hypothermia (Berger et al., 2004). We speculate that drug treatment with bilobalide may offer an alternative to the more risky procedure of hypothermia.

Our results have important implications for bilobalide's site of action. Bilobalide was fully active when given locally (through the microdialysis probe) indicating an action in the brain. In agreement with an earlier study in brain slices (Johns et al., 2002), bilobalide also inhibited glutamate release, at least partially, from hippocampal slices exposed to OGD conditions. Both findings indicate that bilobalide acts locally in brain tissue. But what is the molecular target of bilobalide in ischemic brain? Among the various sources of glutamate 
(Featherstone, 2009), we investigated glutaminase and NAALADase as potential targets. Both enzymes have been shown to release large amounts of glutamate under ischemic conditions, and inhibitors of these enzymes were found to be neuroprotective in experimental stroke models (Newcomb et al., 1997; Slusher et al., 1999). Bilobalide, however, did not inhibit either of these enzymes excluding them as molecular targets of the drug. In fact, recent work suggests that bilobalide somehow prevents cellular energy loss, e.g. by interfering with cellular swelling, mitochondrial ATP production, and apoptosis (Abdel-Kader et al., 2007; Shi et al., 2010), protection of mitochondria against oxidative stress (Longpre et al., 2006; Rhein et al., 2010), or by activation of heme oxygenase-1, an enzyme which is induced by hypoxic conditions (Saleem et al., 2008; Shah et al., 2011). Elucidation of mitochondrial targets of bilobalide is the focus of current work in our laboratory.

\section{Experimental procedures}

\subsection{Experimental stroke model}

Female CD-1 mice (28-32g; Charles River) were kept under standardized $12 \mathrm{~h}$-light/dark, temperature $\left(22^{\circ} \mathrm{C}\right)$ and humidity $(70 \%)$ conditions, with food and water available $\mathrm{ad}$ libitum. Mice were randomized as to treatments, and one vehicle- and one bilobalide-treated mouse were used in parallel on each day of surgery to avoid systematic errors. All animal procedures were in accordance with NIH regulations and were registered with the Institutional Animal Care and Use Committee of TTUHSC and the Regierungspräsidium Darmstadt. All efforts were made to reduce animal suffering.

In vivo-ischemia in the brain was induced as described in detail previously (Mdzinarishvili et al., 2005). Briefly, for permanent occlusion, female CD-1 mice were anesthetized with 1.5 $\%$ isofluorane in $30 \% \mathrm{O}_{2} / 70 \% \mathrm{~N}_{2} \mathrm{O}$. Throughout surgery, body temperature was maintained at $37^{\circ} \mathrm{C}$ by a thermostatic blanket coupled to a rectal thermometer (Harvard/Hugo Sachs, March-Hugstetten, Germany), and cerebral blood flow was monitored by laser Doppler flowmetry (Moor Instruments, Devon, UK). A midline incision was made in the neck to access the left carotid bifurcation and the external (ECA) and internal (ICA) carotid artery. After ligation of the vessels, a small incision was made in the ECA and a monofilament (Doccol Corp., Redlands, CA; filament size 6-0) was inserted and gently advanced through the ICA artery until its tip occluded the origin of the middle cerebral artery (MCA). Correct placement of the suture was indicated by a sudden drop of the local cortical blood flow in the left MCA territory to $15-20 \%$ of basal flow as monitored by laser-Doppler flowmetry. After successful occlusion, the monofilament was secured in place with ligature, and the skin incision was closed by surgical clips. Mice received an i.p. injection of Ringer-lactate solution $(1 \mathrm{~mL})$ and were allowed to recover in their home cage.

For permanent occlusion, MCAO was sustained for a period of $24 \mathrm{~h}$ (Figs. 1, 2 and 4). For transient occlusion (Figs. 3 and 5), surgery was performed as described above, but the thread was left in place for only 75 minutes. Afterwards, the carotid artery was briefly clamped, the thread was removed and the ECA was electrocoagulated. 24 hours after MCAO, mice were deeply anesthetized with isoflurane and euthanised by decapitation. The brains were quickly removed, sectioned coronally into $1 \mathrm{~mm}$ slices, and stained with 2,3,5-triphenyl-tetrazolium chloride (TTC). Images were acquired by a DinoLite camera, and areas of both hemispheres and the infarcted regions were quantified for each slice using Image J 1.30. Analyses were done by the first author (D.L.) and were double-checked by a second member of the lab.

In selected mice $(\mathrm{N}=6)$, blood was withdrawn before $\mathrm{MCAO}$ and $1 \mathrm{~h}$ after MCAO and physiological parameters were measured. Before MCAO, blood pH was $7.41 \pm 0.03$ and hematocrit was $51 \pm 3 \%$. Plasma sodium was $144 \pm 3 \mathrm{mM}$, potassium $5.3 \pm 0.4 \mathrm{mM}$ and 
chloride $108 \pm 4 \mathrm{mM}$. $\mathrm{pO}_{2}$ was $126 \pm 12 \mathrm{~mm} \mathrm{Hg}$ and $\mathrm{pCO}_{2}$ was $38 \pm 5 \mathrm{~mm} \mathrm{Hg}$. All values were within reference range except for the elevated oxygen partial pressure which was due to the increased oxygen content in the gas mixture (30\% vs. $21 \%$ in air). One hour after $\mathrm{MCAO}$, none of these values was significantly changed (data not shown).

\subsection{Microdialysis procedure}

Probe implantation was done one day prior to MCAO. Mice were anesthetized with isofluorane (induction dose 3\%, maintenance dose $1.5 \% \mathrm{v} / \mathrm{v}$ ) in a 30\%/70\% mixture of oxygen and nitrous oxide and placed in a stereotaxic frame. Self-made, I-shaped, concentric dialysis probes with an exchange length of 2-2.5 $\mathrm{mm}$ were implanted in the left striatum using the following coordinates (from bregma): striatum, AP $+0.5 \mathrm{~mm} ; \mathrm{L}+2.2 \mathrm{~mm}$; DV -3.8 $\mathrm{mm}$. Hippocampal coordinates (see Fig. 4) were AP $-2.0 \mathrm{~mm}$; L +2.0 mm; DV $-2.3 \mathrm{~mm}$ (Franklin and Paxinos, 1997). Mice were allowed to recover over night in their home cage.

Perfusion of the microdialysis probe was started one hour before MCAO, was sustained while the MCAO surgery was performed, and was continued until 2 hours after MCAO. The perfusion fluid was artificial cerebrospinal fluid (aCSF; $147 \mathrm{mM} \mathrm{NaCl}, 4 \mathrm{mM} \mathrm{KCl}, 1.2 \mathrm{mM}$ $\mathrm{CaCl}_{2}$ and $1.2 \mathrm{mM} \mathrm{MgCl}$ ). The perfusion rate was $2 \mu \mathrm{l} / \mathrm{min}$, and efflux from the microdialysis probe was collected in intervals of 10 minutes.

\subsection{Drug administration}

Bilobalide (or vehicle, 10\% DMSO in saline) was injected intraperitoneally 60 min before induction of ischemia, or 1 or 3 hours after ischemia, at doses of $0.3-10 \mathrm{mg} / \mathrm{kg}$. In the infusion study (Fig. 5), bilobalide was added to the perfusion fluid in a concentration of 10 $\mu \mathrm{M}$. Controls received $0.1 \%$ DMSO in saline by infusion.

\subsection{Chemical analysis of microdialysates}

Metabolite concentrations in the microdialysis samples were determined by a CMA 600 microanalyzer (CMA, Stockholm, Sweden) using a kinetic photometric assay as described by the manufacturer. The following metabolites were measured (lower limits of detection in parentheses): glucose $(0.02 \mathrm{mM})$, lactate $(0.02 \mathrm{mM})$, and glutamate $(1.0 \mu \mathrm{M})$. In vitrorecoveries were determined by dialysis of analytes from unstirred vials containing a fixed concentration (100-times the detection limit) of analytes.

\subsection{Neurobehavioral testing}

The behavioral tests were performed in the morning before surgery and 24 hours after MCAO. Results in Fig. 3 were obtained after transient ischemia $(75 \mathrm{~min}$ ) because permanent MCAO caused too strong damage to test the mice (data not shown). The "Corner test" was used as described (Zhang et al., 2002). Each mouse was tested for one trial (max. time 120 sec) before and after surgery and the chosen sides were counted. The normalized laterality index (nLI) was calculated as described (Bouet et al., 2007). The "Chimney test" (Heinecke, 1987) was performed for each mouse three times before and after surgery. A mouse was placed head in front at the entry of a tube $(200 \mathrm{~mm}$ long and $20 \mathrm{~mm}$ in diameter). When the mouse reached the bottom of the tube, the tube was raised in a vertical position. All mice react by walking backwards. The time needed to climb out of the tube was measured for a maximum of $120 \mathrm{sec}$.

\subsection{Enzymatic assays}

Mouse forebrains, separated from the cerebellum, were homogenized in $1 \mathrm{~mL}$ ice-cold 20 $\mathrm{mM}$ Tris- $\mathrm{HCl}$ buffer ( $\mathrm{pH} 7.4$ ), and the homogenate was dialyzed in 100-fold volume of the buffer for 24 hours at $4^{\circ} \mathrm{C}$. Aliquots were stored at $-80^{\circ} \mathrm{C}$. Glutaminase activity was 
quantified by determination of the rate of glutamate release from glutamine as previously described (Newcomb et al., 1997). Briefly, brain homogenates were incubated with or without inhibitors ( $2 \mathrm{mM}$ 6-diazo-5-oxo-L-norleucine, DON, or $10 \mu \mathrm{M}$ bilobalide) and with $2 \mathrm{mM}$ glutamine at $37^{\circ} \mathrm{C}$. Glutamate levels were measured in aliquots taken from the incubation mixture at the beginning of the incubation and after 60 min using the CMA-600 microanalyzer (see above). NAALADase ( $\mathrm{N}$-acetylated- $\alpha$-linked acidic dipeptidase) activity was quantified by determination of the extent of the hydrolysis of ${ }^{3} \mathrm{H}-\mathrm{N}$-acetylaspartateglutamate (NAAG) as previously described (Tiffany et al., 2002). Briefly, brain homogenates were incubated with cofactors and with or without inhibitors $(100 \mu \mathrm{M} 2$ phosphonomethyl-pentanedioic acid, PMPA, or $10 \mu \mathrm{M}$ bilobalide) and $30 \mathrm{nM}^{3} \mathrm{H}-\mathrm{NAAG}$ for $15 \mathrm{~min}$. The incubation was stopped by addition of ice-cold methanol and centrifugation. Aliquots of supernatants were separated together with control samples (NAAG, NAA and glutamate) by thin-layer chromatography (TLC). After detection by ninhydrin, spots corresponding to NAAG and glutamate were scraped and radioactivity associated with the spots was measured with a scintillation counter.

\subsection{Measurement of ${ }^{3} \mathrm{H}$-glutamate release from striatal slices}

These experiments were performed as previously described for ${ }^{3} \mathrm{H}$-glycine release (Kiewert et al., 2008). Briefly, striatal slices $(400 \mu \mathrm{m})$ were prepared from female CD-1 mice and superfused $(0.7 \mathrm{ml} / \mathrm{min})$ at $35^{\circ} \mathrm{C}$ with Tyrode solution which was gassed with carbogen. All slices were pre-incubated for $15 \mathrm{~min}$ with ${ }^{3} \mathrm{H}$-glutamate $(5 \mu \mathrm{Ci} ; 185 \mathrm{kBq})$; then, they were randomly transferred to four lanes (A-D) of a superfusion chamber and were superfused for 40 min. At time zero (cf. Fig. 6), lanes A and C were switched to Tyrode solution containing $0.1 \%$ DMSO while lanes B and D were superfused with Tyrode solution containing $10 \mu \mathrm{M}$ bilobalide (in 0.1\% DMSO), respectively. 5 min later, the slices in lanes C and D underwent oxygen-glucose deprivation (OGD), i.e. they were superfused with Tyrode solution that lacked glucose and was gassed with nitrogen instead of carbogen. The effluent from each lane was collected in 5 min intervals, mixed with scintillation fluid and counted in a Beckman Coulter LS 6000 scintillation counter. At the end of the incubation, the slices from each lane were collected, homogenized, and aliquots were also counted for radioactivity. Data were expressed as [\%] of radioactivity that was released during a given time period, relative to the total radioactivity present in the tissue at that time. Areas under the curve (AUC) values were calculated for each individual experiment; they represent the amount of radioactivity that was released during $30 \mathrm{~min}$ of superfusion (Fig. 6B).

The identity of tritium release as ${ }^{3} \mathrm{H}$-glutamate was confirmed by TLC as previously described (Kiewert et al., 2008). ${ }^{3} \mathrm{H}$-glutamate accounted for $>85 \%$ of total radioactivity in effluents and homogenates (data not shown).

\subsection{Statistical analysis}

Data are given as mean \pm S.E.M. of $N$ experiments. Data in Figs. 1-3 and 6 were compared by one-way ANOVA. Time courses of microdialysis data (Figs. 4-5) were compared by two-way ANOVA for repeated measurements (software: GraphPad Prism 5.0).

\section{Acknowledgments}

This study was supported by NIH grant R21AT003399 to J.K., and by intramural funds of Goethe University. The authors are grateful to Drs. Shyam S. Chatterjee, M. Nöldner and C. Erdelmeier, Schwabe Co., Karlsruhe, Germany, for supplying pure bilobalide. 


\section{Abbreviations}

MCAO middle cerebral artery occlusion

\section{REFERENCES}

Abdel-Kader R, Hauptmann S, Keil U, Scherping I, Leuner K, Eckert A, Müller WE. Stabilization of mitochondrial function by Ginkgo biloba extract (EGb 761). Pharmacol. Res. 2007; 56:493-502. [PubMed: 17977008]

Ahlemeyer B, Möwes A, Krieglstein J. Inhibition of serum deprivation- and staurosporine-induced neuronal apoptosis by Ginkgo biloba extract and some of its constituents. Eur. J. Pharmacol. 1999; 367:423-430. [PubMed: 10079019]

Ahlemeyer B, Krieglstein J. Neuroprotective effects of Ginkgo biloba extract. Cell. Mol. Life Sci. 2003; 60:1779-1792. [PubMed: 14523543]

Berger C, Schabotz WR, Wolf M, Mueller H, Sommer C, Schwab S. Hypothermia and brain-derived factor reduce glutamate synergistically in acute stroke. Exp. Neurol. 2004; 185:305-312. [PubMed: 14736512]

Biber A. Pharmacokinetics of Ginkgo biloba extracts. Pharmacopsychiatry. 2003; 36(Suppl. 1):S32S37. [PubMed: 13130386]

Birks J, Grimley EJ. Ginkgo biloba for cognitive impairment and dementia. Cochrane Database Syst. Rev. 2009:CD003120. [PubMed: 19160216]

Bouet V, Freret T, Toutain J, Divoux D, Boulouard M, Schumann-Bard P. Sensorimotor and cognitive deficits after transient middle cerebral artery occlusion in the mouse. Exp Neurol. 2007; 203:555567. [PubMed: 17067578]

Chandrasekaran K, Mehrabian Z, Spinnewyn B, Drieu K, Fiskum G. Neuroprotective effects of bilobalide, a component of the Ginkgo biloba extract (EGb761), in gerbil global brain ischemia. Brain Res. 2001; 922:282-292. [PubMed: 11743961]

Danton GH, Dietrich WD. The search for neuroprotective strategies in stroke. AJNR Am. J. Neuroradiol. 2004; 25:181-194. [PubMed: 14970016]

DeFeudis FV. Bilobalide and neuroprotection. Pharmacol. Res. 2002; 46:565-568. [PubMed: 12457632]

Featherstone DE. Intercellular glutamate signaling in the nervous system and beyond. ACS Chem. Neurosci. 2009 DOI: 10.1021/cn900006n.

Franklin, KB.; Paxinos, G. The mouse brain in stereotaxic coordinates. Academic Press; San Diego: 1997.

Ginsberg MD. Neuroprotection for ischemic stroke: Past, present and future. Neuropharmacology. 2008; 55:363-389. [PubMed: 18308347]

Heinecke H. A comparison of two variants of the chimney behaviour test in mice. Z. Versuchstierkunde. 1987; 29:145-148.

Horn T, Klein J. Lactate levels in the brain are elevated upon exposure to volatile anesthetics: a microdialysis study. Neurochem. Int. 2010; 57:940-947. [PubMed: 20933036]

Johns L, Sinclair AJ, Davies JA. Effects of bilobalide on hypoxia/hypoglycemia-stimulated glutamate efflux from rat cortical brain slices. Neurochem. Res. 2002; 27:369-371. [PubMed: 12064351]

Kiewert C, Kumar V, Hildmann O, Hartmann J, Hillert M, Klein J. Role of glycine receptors and glycine release for the neuroprotective activity of bilobalide. Brain Res. 2008; 1201:143-150. [PubMed: 18325484]

Kiewert C, Mdzinarishvili A, Hartmann J, Bickel U, Klein J. Metabolic and transmitter changes in core and penumbra after middle cerebral artery occlusion in mice. Brain Res. 2010; 1312:101-107. [PubMed: 19961839]

Klein J, Chatterjee SS, Löffelholz K. Phospholipid breakdown and choline release under hypoxic conditions: inhibition by bilobalide, a constituent of Ginkgo biloba. Brain Res. 1997; 755:347350. [PubMed: 9175905] 
Lang D, Ude C, Wurglics M, Schubert-Zsilavecs M, Klein J. Brain permeability of bilobalide as probed by microdialysis before and after middle cerebral artery occlusion in mice. J. Pharm. Pharm. Sci. 2010; 13:607-614. [PubMed: 21486534]

Lee EJ, Chen HY, Wu TS, Chen TY, Ayoub IA, Maynard KI. Acute administration of Ginkgo biloba extract (EGb 761) affords neuroprotection against permanent and transient focal cerebral ischemia in Sprague-Dawley rats. J. Neurosci. Res. 2002; 68:636-645. [PubMed: 12111854]

Lipton P. Ischemic cell death in brain neurons. Physiol. Rev. 1999; 79:1431-1568. [PubMed: 10508238]

Mdzinarishvili A, Geldenhuys WJ, Abbruscato TJ, Bickel U, Klein J, van der Schyf CJ. NGP1-01, a lipophilic polycyclic cage amine, is neuroprotective in focal ischemia. Neurosci. Lett. 2005; 383:49-53. [PubMed: 15936510]

Mdzinarishvili A, Kiewert C, Kumar V, Hillert M, Klein J. Bilobalide prevents ischemia-induced edema formation in vitro and in vivo. Neuroscience. 2007; 144:217-222. [PubMed: 17014966]

Mehta SL, Manhas N, Raghubir R. Molecular targets in cerebral ischemia for developing novel therapeutics. Brain Res. Rev. 2007; 54:34-66. [PubMed: 17222914]

Newcomb R, Sun X, Taylor L, Curthoys N, Giffard RG. Increased production of extracellular glutamate by the mitochondrial glutaminase following neuronal death. J. Biol. Chem. 1997; 272:11276-11282. [PubMed: 9111031]

Shah ZA, Nada SE, Dore S. Heme oxygenase-1, beneficial role in permanent ischemic stroke and in Ginkgo biloba (EGb 761) neuroprotection. Neuroscience. 2011; 180:248-255. [PubMed: 21334424]

Shi C, Wu F, Yew DT, Xu J. Bilobalide prevents apoptosis through activation of the PI3K/Akt pathway in SH-SY5Y cells. Apoptosis. 2010; 15:715-727. [PubMed: 20333467]

Slusher BS, Vornov JJ, Thomas AG, Hurn PD, Harukuni I, Bhardwaj A, Traystman RJ, Robinson MB, Britton P, Lu XC, Tortella FC, Wozniak KM, Yudkoff M, Potter BM, Jackson PF. Selective inhibition of NAALADase, which converts NAAG to glutamate, reduces ischemic brain injury. Nat. Med. 1999; 5:1396-1402. [PubMed: 10581082]

Szydlowska K, Tymianski M. Calcium, ischemia and excitotoxicity. Cell Calcium. 2010; 47:122-129. [PubMed: 20167368]

Tiffany CW, Slusher BS. NAALADase assay. Current Protocols in Pharmacology. 2001:3.10.13.10.12.

Weichel O, Hilgert M, Chatterjee SS, Lehr M, Klein J. Bilobalide, a constituent of Ginkgo biloba, inhibits NMDA-induced phospholipase $\mathrm{A}_{2}$ activation and phospholipid breakdown in rat hippocampus. Naunyn-Schmiedeberg's Arch. Pharmacol. 1999; 360:609-615. [PubMed: 10619176]

Woodruff TM, Thundyil J, Tang SC, Sobey CG, Taylor SM, Arumugam TV. Pathophysiology, treatment, and animal and cellular models of human ischemic stroke. Mol. Neurodeger. 2011; 25:11.

Zeng X, Liu M, Yang Y, Li Y, Asplund K. Ginkgo biloba for acute ischemic stroke. Cochrane Database Syst. Rev. 2005; 4:CD003691. [PubMed: 16235335]

Zhang L, Schallert T, Zhang ZG, Jiang Q, Arniego P, Li Q, Lu M, Chopp M. A test for detecting longterm sensorimotor dysfunction in the mouse after focal cerebral ischemia. J. Neurosci. Methods. 2002; 117:207-214. [PubMed: 12100987] 


\section{Highlights for Lang et al.}

Bilobalide is a neuroprotective compound present in Ginkgo biloba extracts

$>$ Pure bilobalide (1-10 $\mathrm{mg} / \mathrm{kg}$ ) reduces neuronal cell death after brain ischemia

Bilobalide appears to act locally in the infarcted brain

$>$ The mechanism of action involves reduction of ischemia-induced glutamate release 

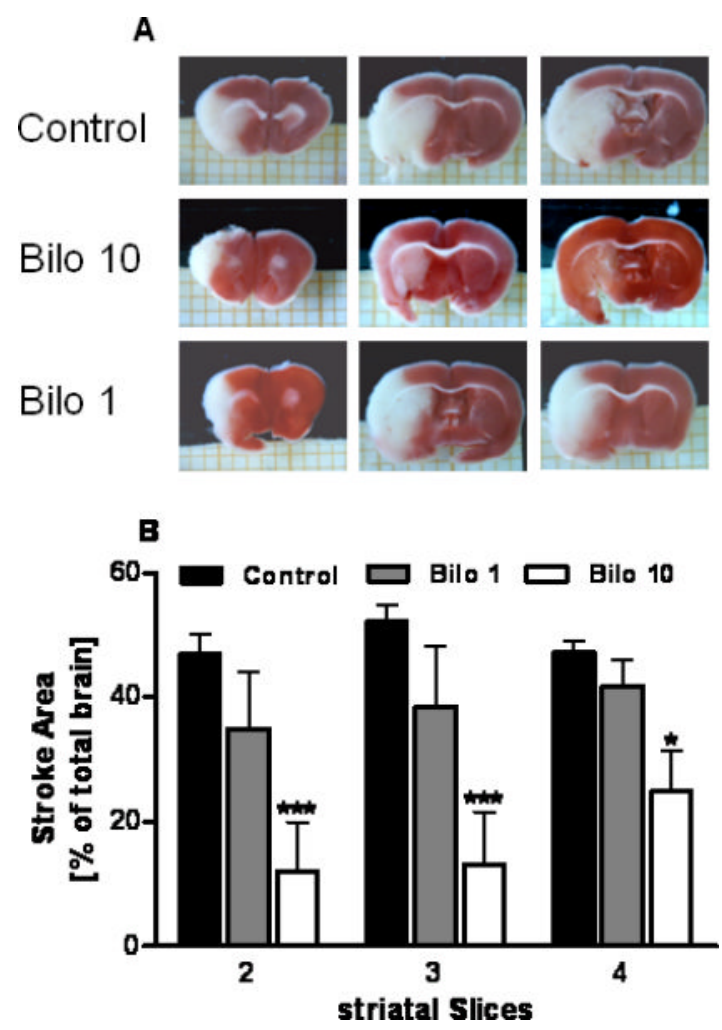

Fig. 1.

Dose-dependent effect of bilobalide on striatal infarct areas induced by middle cerebral artery occlusion (MCAO) in mice. - Upper panel: Mice were treated with vehicle $(0.3 \mathrm{ml}$ saline i.p. containing 10\% DMSO, "Control"), $1 \mathrm{mg} / \mathrm{kg}$ bilobalide ("Bilo 1") or $10 \mathrm{mg} / \mathrm{kg}$ bilobalide ("Bilo 10") one hour prior to MCAO. The animals were sacrificed 24 hours past MCAO, six slices of $1 \mathrm{~mm}$ thickness were cut coronally and stained by tetrazolium chloride (TTC). Areas with insufficient mitochondrial activity to reduce TTC are indicated by pale white colour. Lower panel: Infarct areas were calculated as percentage of infarct area over total brain area in each slice. The numbers refer to the slices starting at the caudal end of the mouse brain; 2, 3 and 4 represent striatal slices. Nine mice were used in each treatment group; due to mortality of two mice per group, data are expressed as mean \pm S.E.M. of $\mathrm{N}=7$ experiments. ${ }^{* *}, \mathrm{p}<0.01 ; * * *, \mathrm{p}<0.001$ vs. Control. 

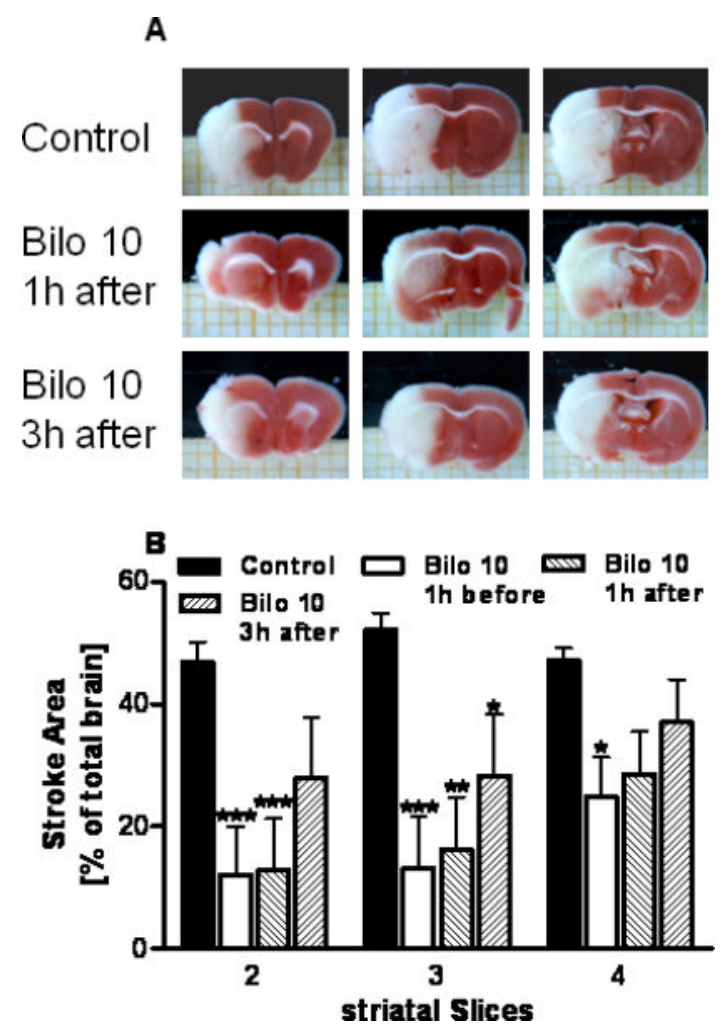

Fig. 2.

Time-dependent effects of bilobalide on striatal infarct areas induced by middle cerebral artery occlusion (MCAO) in mice. - Upper panel: Mice were treated with vehicle $(0.3 \mathrm{ml}$ saline i.p. containing 10\% DMSO, "Control"), or $10 \mathrm{mg} / \mathrm{kg}$ bilobalide $1 \mathrm{~h}$ after or $3 \mathrm{~h}$ after MCAO. Brain slices were prepared and stained with TTC as described in Fig. 1. Lower panel: Infarct areas were calculated as percentage of infarct area over total brain area in each slice; data from bilobalide given prior to MCAO ("Bilo 10", cf. Fig. 1) were included for comparison. Nine mice were used in each group; due to mortality of two mice per group, data are expressed as mean \pm S.E.M. of $\mathrm{N}=7$ experiments. *, $\mathrm{p}<0.05$; **, $\mathrm{p}<0.01$; ***, $\mathrm{p}<0.001$ vs. Control. 

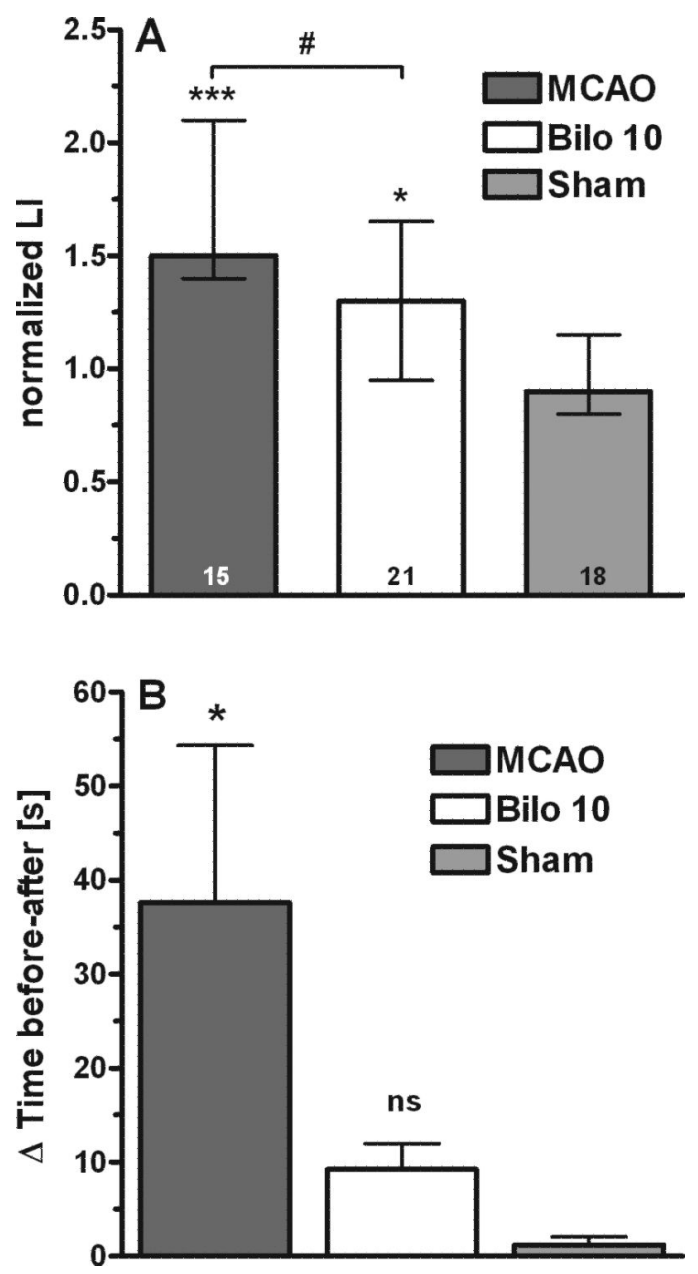

Fig. 3.

Effects of bilobalide treatment in neurobehavioral tests. - (A) Corner test. Performances are expressed by the normalized laterality index ("nLI"; with medians and their interquartile ranges) for each group of mice, i.e. sham-operated mice ("Sham"), mice that sustained MCAO and were treated with vehicle ("MCAO"), and mice that sustained MCAO having been treated with $10 \mathrm{mg} / \mathrm{kg}$ bilobalide $1 \mathrm{~h}$ before stroke ("Bilo 10"). Numbers in the columns indicate mice per group. Statistical significances were calculated by one-way ANOVA and Bonferroni's Multiple Comparison Test. *, p<0.05; ***p<0.001 vs. Sham; \#, p<0.05 vs. MCAO. (B) Chimney test. Performances are expressed as time (s) to get out of the tube and were calculated as difference between time needed before and after surgery. Results are mean \pm S.E.M of 10 experiments. Statistical significances were calculated by one-way ANOVA and Bonferroni's Multiple Comparison Test for treatment vs sham; *p< 0.05 vs. Sham; ns, not significant vs. Sham. 

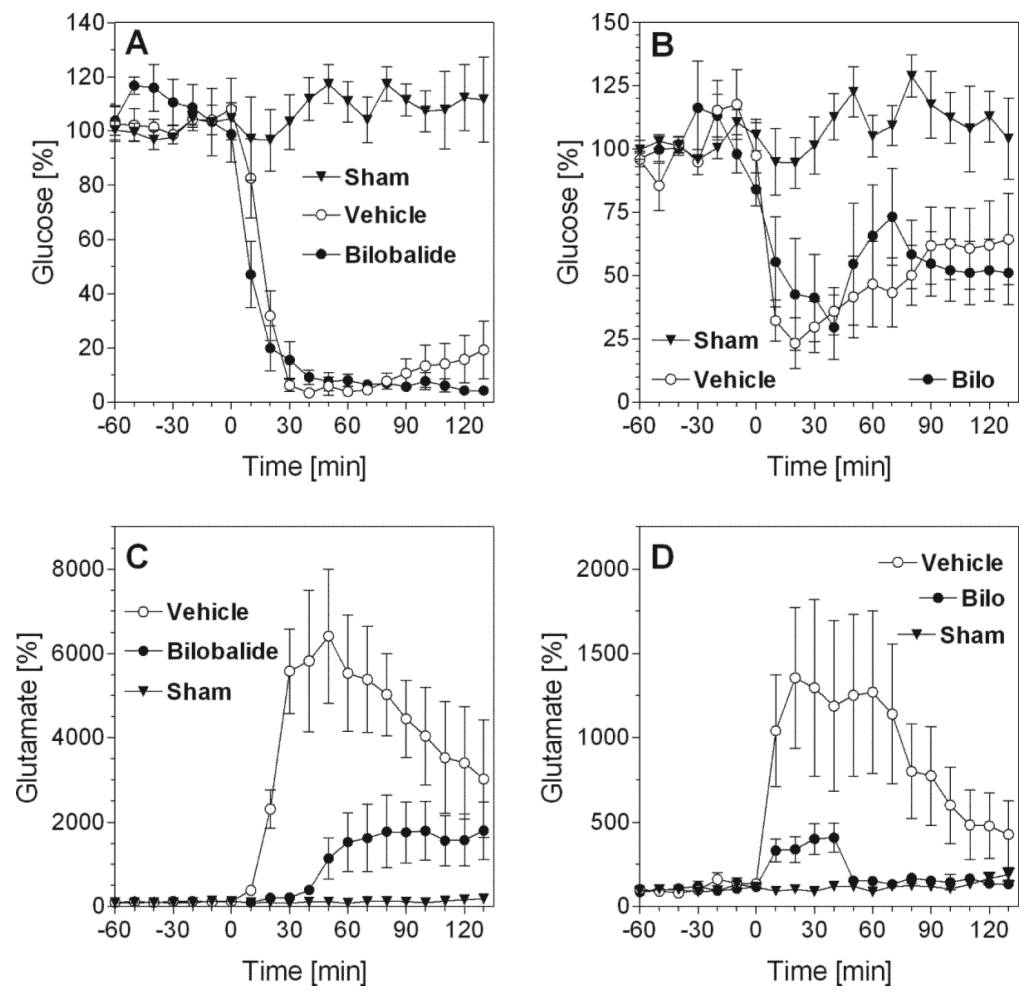

Fig. 4.

Effects of bilobalide on extracellular glucose and glutamate levels before and after MCAO. (A) Striatal glucose levels. (B) Hippocampal glucose levels. (C) Striatal glutamate levels. (D) Hippocampal glutamate levels. The figures show concentrations measured from $60 \mathrm{~min}$ before induction of stroke (MCAO, at time zero) to $130 \mathrm{~min}$ past stroke. Experiments were done in three groups of mice: sham-operated mice ("Sham"), vehicle-treated mice with MCAO ("Vehicle") and bilobalide-treated mice with MCAO ("Bilobalide") (N=6 each). Bilobalide was dissolved in vehicle (10\% DMSO in saline) and was given by i.p. injection one hour before $\mathrm{MCAO}$ at a dose of $10 \mathrm{mg} / \mathrm{kg}$. Data are percentages (means \pm S.E.M.) of basal concentrations which were determined as averages from the measured samples prior to MCAO (see Results for basal values). Statistical analysis (two-way ANOVA for repeated measurements, GraphPad Prism ${ }^{\circledR}$ ): (A) All curves: $F_{2,15}=116.9$, $p<0.01$; glucose ("Vehicle") vs. glucose ("Bilobalide"), $\mathrm{F}_{1,10}=0.26, \mathrm{p}=0.63$. (B) All curves: $\mathrm{F}_{2,13}=6.66$, $\mathrm{p}=0.01$; glucose ("Vehicle") vs. glucose ("Bilo"), $\mathrm{F}_{1,10}=0.08, \mathrm{p}=0.78$. (C) All curves: $\mathrm{F}_{2,15}=16.36$; $\mathrm{p}<0.01$; glutamate ("Vehicle") vs. glutamate ("Bilobalide"), $\mathrm{F}_{1,10}=11.06$; $\mathrm{p}<0.01$. (D) All curves: $\mathrm{F}_{2,15}=5.15 ; \mathrm{p}=0.02$; glutamate ("Vehicle") vs. glutamate ("Bilobalide"), $\mathrm{F}_{1,10}=4.48 ; \mathrm{p}=0.06$. 

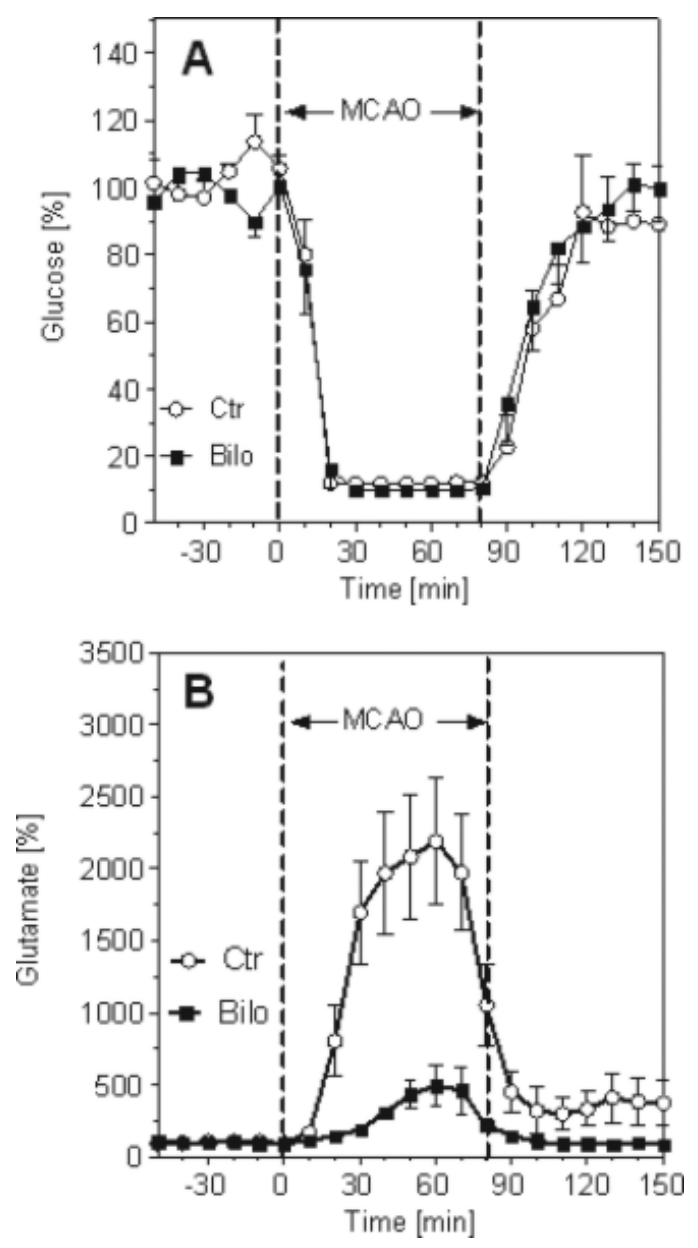

Fig. 5.

Effects of locally applied bilobalide on (A) glucose and (B) glutamate levels after MCAO as measured by microdialysis in mouse striatum. - The figure shows extracellular concentrations measured from $50 \mathrm{~min}$ before induction of stroke (MCAO, at time zero) to 150 min past stroke $(\mathrm{N}=6)$. Bilobalide $(10 \mu \mathrm{M})$ was continuously infused through the microdialysis probe, and MCAO was induced from 0-75 min as indicated. Data are percentages (means \pm S.E.M.) of basal release which was determined as average efflux from the measured samples prior to treatment. Statistical analysis (two-way ANOVA for repeated measurements, GraphPad Prism ${ }^{\circledR)}$ ): (A) Glucose ("Ctr") vs. glucose ("Bilo"), $\mathrm{F}_{1,10}=0.03$; $\mathrm{p}=0.87$. (B) Glutamate ("Ctr") vs. glutamate ("Bilo"), $\mathrm{F}_{1,10}=20.17 ; \mathrm{p}<0.01$. 

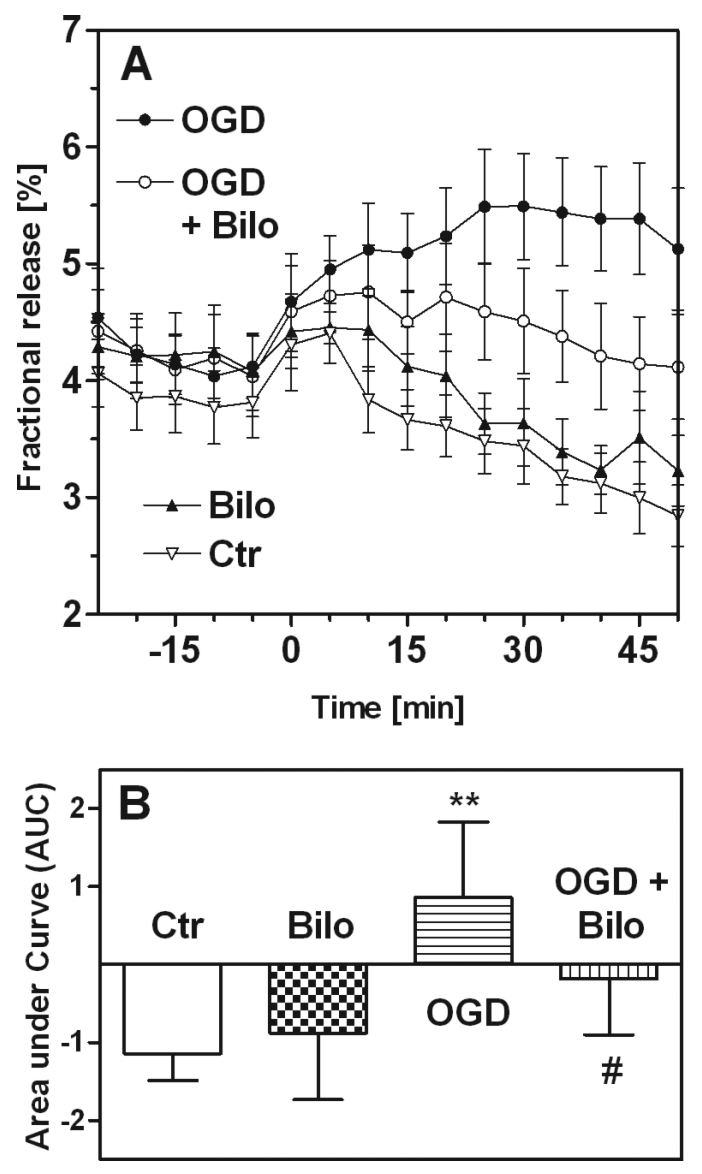

Fig. 6.

Effects of bilobalide on ischemia-induced glutamate release in vitro. - Mouse striatal slices were preloaded with ${ }^{3} \mathrm{H}$-glutamate and then superfused in four lanes in the presence ("Bilo") or absence ("Ctr") of bilobalide $(10 \mu \mathrm{M})$. At time zero, two lanes were switched to a buffer solution containing no glucose which was bubbled with nitrogen (oxygen-glucose deprivation, “OGD”). (A) Efflux of ${ }^{3} \mathrm{H}$-glutamate was monitored by scintillation counting and expressed as fractional release. (B) Areas under the curve for the release curves shown in A. Statistical analysis (paired two-way ANOVA, GraphPad Prism®): **, p<0.01 vs. Ctr; \#, $\mathrm{p}<0.05$ vs. OGD. 


\section{Table 1}

Effect of bilobalide on glutaminase and NAALADase activities

\begin{tabular}{lll}
\hline Assay/Inhibitor & Glutaminase activity [ $\boldsymbol{\mu M}$ glutamate released] & NAALADase activity [cpm ${ }^{3} \mathbf{H}$-glutamate released] \\
\hline Control & $44.97 \pm 24.09$ & $1054 \pm 278$ \\
DON $(2 \mathrm{mM})$ & $4.27 \pm 2.01^{* * *}$ & ND \\
PMPA $(100 \mu \mathrm{M})$ & $\mathrm{ND}$ & $56 \pm 18^{* * *}$ \\
Bilobalide & $49.51 \pm 26.18$ & $846 \pm 426$ \\
DMSO $(0.1 \%)$ & $37.25 \pm 16.36$ & $1069 \pm 316$ \\
\hline
\end{tabular}

For glutaminase assay, brain homogenates were incubated with glutamine and (as indicated) with DON, bilobalide or DMSO (vehicle) (see Methods). Glutaminase was expressed as $[\mu \mathrm{M}]$ glutamate formed by $1 \mathrm{mg}$ protein in $60 \mathrm{~min}$. Data are mean \pm S.D., N=5. For NAALADase assay, brain homogenates were incubated for 15 min with ${ }^{3} \mathrm{H}-\mathrm{NAAG}$ and (as indicated) with PMPA, bilobalide or DMSO (vehicle) (see Methods). NAALADase activity was expressed as [cpm ${ }^{3} \mathrm{H}$-glutamate] formed by $1 \mathrm{mg}$ protein in $90 \mathrm{~min}$. Data are mean $\pm \mathrm{S} . \mathrm{D}$., N=6-7. Statistics for both assays: one-way ANOVA with Dunnett's post-test.

$* * *$

p $<0.001$ vs Control. 